\title{
Erratum to: Price discrimination through multi-level loyalty programs
}

\author{
Serdar Sayman $^{1} \cdot$ Murat Usman $^{1}$
}

Published online: 14 October 2015

(C) Springer Science+Business Media New York 2015

\section{Erratum to: Mark Lett (2015) \\ DOI 10.1007/s11002-015-9385-7}

The published article unfortunately contained mistakes. The presentations of equations found in Proposition 4 and Proof of Proposition 4 were incorrect. However, these have been addressed and the original article was corrected. The equations were corrected as follows:

Proposition 4 When there are light users in the market, offering both $\bar{R}_{n / 2}$ and $R_{n}$ is more profitable than offering only $R_{n}$ if $\frac{(P-c)}{k}>\Phi$

\section{Proof of Proposition 4}

$\Pi_{2}-\Pi_{1}>0$ if $\frac{(P-c)}{k}>\frac{B}{A}$, and we know that $\frac{B}{A}>0$. We let $\Phi=\frac{B}{A}$.

The online version of the original article can be found at http://dx.doi.org/10.1007/s11002-015-9385-7.

Serdar Sayman

ssayman@ku.edu.tr

Murat Usman

musman@ku.edu.tr

1 College of Administrative Sciences and Economics, Koç University, Rumeli Feneri Yolu, Sariyer 34450 Istanbul, Turkey 